ISSN Print : $1411-951 \mathrm{X}$, ISSN Online : 20503-1716

Jurnal Ergonomi Indonesia

(The Indonesian Journal of Ergonomic)

Vol.2, No.1 : 1 Januari-Juni 2016

\title{
PENGGUNAAN DINNER PLATE YANG ANTROPOMETRIS PADA AMERICAN SERVICE MENINGKATKAN KINERJA PELAYANAN MAHASISWA PRAKTEK DI RESTORAN SEKOLAH TINGGI PARIWISATA NUSA DUA BALI
}

\author{
Ni Putu Ariesta Budiani ${ }^{1}$, I Nyoman Adiputra ${ }^{2}$, I Wayan Surata ${ }^{3}$ \\ Program Studi Ergonomi-Fisiologi Kerja, Program Pascasarjana Universitas Udayana \\ Email; ariestabud@gmail.com ${ }^{1}$
}

\begin{abstract}
ABSTRAK
Pelayanan ala Amerika (American Service) mengutamakan kecepatan dan ketepatan seorang pramusaji di dalam melakukan pelayanannya. Oleh karenanya seorang pramusaji diharuskan untuk mampu membawa maksimum empat piring sekaligus ketika melakukan pelayanan. Penggunaan peralatan makan yang tidak antropometris berpotensi menimbulkan keluhan muskuloskeletal dan kelelahan, serta dapat mempengaruhi kinerja pelayanan di restoran. Untuk itu perlu dilakukan penerapan ergonomi dengan mengganti peralatan yang lebih antropometris bagi pemakainya.

Penelitian ini merupakan penelitian eksperimental dengan menggunakan rancangan randomized pre and post test kontrol group design. Penelitian ini melibatkan 36 orang mahasiswa semester empat program studi Manajemen Tata Hidangan, Diploma III, Sekolah Tinggi Pariwisata, Nusa Dua Bali sebagai subjek yang dipilih secara random.

Berdasarkan uji beda kemaknaan diperoleh perbedaan yang signifikan antara kelompok kontrol dan kelompok perlakuan. Pada kelompok perlakuan telah terjadi penurunan keluhan subjektif yang meliputi keluhan muskuloskeletal sebesar 38,7\% dan kelelahan secara umum sebesar $42,9 \%$. Begitu juga dengan lama waktu penyajian terjadi penurunan sebesar $36,86 \%$, sedangkan kualitas penyajian terjadi peningkatan sebesar 65,01 $\%$. Hal ini terjadi karena penggunaan piring yang lebih antropometris yaitu penggunaan dinner plate yang lebih ringan 410 gr dan memiliki diameter $4,2 \mathrm{~cm}$ lebih kecil dari piring sebelumnya sehingga lebih nyaman dibawa sekaligus empat saat menyajikan ke meja tamu. Hal ini menunjukkan adanya peningkatan kinerja pelayanan.

Disimpulkan bahwa penerapan ergonomi berupa penggunaan peralatan makan yang antropometris pada American service dapat meningkatkan kinerja pelayanan mahasiswa praktek di restoran.
\end{abstract}

Kata Kunci : Dinner plate, antropometri, american service, kinerja 
ISSN Print : $1411-951 \mathrm{X}$, ISSN Online : 20503-1716

Jurnal Ergonomi Indonesia

(The Indonesian Journal of Ergonomic)

Vol.2, No.1 : 1 Januari-Juni 2016

\title{
THE APPLICATION OF ANTROPOMETRIC DINNER PLATE IN AMERICAN \\ SERVICE CAN IMPROVE SERVICE PERFORMANCE AMONG PRACTICE STUDENTS AT THE RESTAURANT AT NUSA DUA BALI TOURISM INSTITUTE
}

\begin{abstract}
American-style service (American Service) priority to speed and accuracy among waitress while did the ministry. Therefore a waitress required to be able to carry a maximum of four plates at a time when doing service. The application of inappropriate tableware may associate with musculoskeletal complaints and fatigue, and affect the service performance in the restaurant. It is necessary for the application of ergonomic aspect especially appropriate equipment.

This research was using an experimental study with the pre and post test control group design. This study involved fourth semester students, Restaurant Management Third Diploma of Nusa Dua Bali Tourism Institute as a subject as many as 36 people.

The result showed significantly difference between control and treatment groups. In the treatment group had decreased subjective complaints that include musculoskeletal disorders about $38.7 \%$ and general fatigue about $42.9 \%$. The length of presentation time decline $36.86 \%$, while the quality of the presentation increased $65.01 \%$. The decrease in subjective complaints occurred because the application of anthropometric dinner plate that lighter 410 grams and has a shorter diameter $4.2 \mathrm{~cm}$ than previous plate. It is more convenient to carry even four at the time when presents to the guests. This is also showed an increase in service performance.

It can be concluded that the ergonomics application of using appropriate anthropometric equipment in the American Service can improve the service performance among practice students in restaurant.
\end{abstract}

Keywords : Dinner plate, anthropometric, American Service, performance 
ISSN Print : 1411 -951 X, ISSN Online : 20503-1716

Jurnal Ergonomi Indonesia

(The Indonesian Journal of Ergonomic)

\section{PENDAHULUAN}

Kemampuan membawa empat piring makan sekaligus dengan benar merupakan salah satu kemampuan atau kompetensi yang harus dimiliki seorang pramusaji. Hal ini akan menunjukkan kemampuan seorang pramusaji bekerja secara profesional. Penggunaan peralatan makan yang besar dan berat (chop plate) dalam penyajian makanan ke meja tamu dengan American style (American service), mengutamakan kecepatan (efisien) dan ketepatan (efektif) dalam pelayanannya. Sehingga mengharuskan seorang pramusaji dalam hal ini mahasiswa yang melakukan praktek di restoran untuk membawa piring lebih banyak (maksimum empat piring sekaligus). Teknik membawa piring pada tangan kiri sama prinsipnya dengan sistem pengungkit pada biomekanika pekerja manual handling, dimana apabila lebar lengan beban (jarak dari ujung ibu jari ke tepi paling luar piring) dan berat beban makin tinggi maka makin tinggi moment atau gaya yang diperlukan untuk menjaga keseimbangan agar piring tidak jatuh. Hal ini dapat meningkatkan beban kerja sehingga dapat menimbulkan keluhan subjektif berupa meningkatnya kelelahan dan keluhan muskuloskeletal pada tangan (khususnya saat menyajikan makanan utama), serta akan berdampak terhadap kecepatan pelayanan dan penampilan makanan (kualitas penyajian). Hal ini berpotensi menimbulkan keluhan dari tamu.

\section{MATERI DAN METODE}

Penelitian ini merupakan penelitian eksperimental dengan rancangan randomized pre and post test control group design, dimana pada periode satu subjek menyajikan makanan dengan chop plate, dan pada periode dua subjek menyajikan makanan dengan dinner plate. Pengukuran keluhan muskuloskeletal menggunakan kuesioner Nordic Body Map, kelelahan dengan kuesioner 30 item kelelahan, stopwatch untuk mengukur waktu penyajian dan cheklist penilaian kualitas. Data yang telah diperoleh dianalisis secara deskriptif untuk mencari rerata, simpang baku dan rentangan, kemudian dilakukan uji normalitas dengan uji Shapiro-Wilk pada tingkat kemaknaan $(\alpha=0,05)$ dan uji beda kemaknaan dengan uji $t$ - Independent Sample. Kriteria pengujian menggunakan taraf signifikansi $5 \%(\alpha=0,05)$.

\section{HASIL DAN PEMBAHASAN}

Berdasarkan hasil wawancara, pengisian kuesioner, dan pengukuran diketahui bahwa rerata umur subjek adalah $19,47 \pm 0,91$ tahun. Sedangkan rerata indeks massa tubuh subjek adalah 21,53 \pm 1,57. Berdasarkan dari umur dan indeks 
ISSN Print : 1411 -951 X, ISSN Online : 20503-1716

Jurnal Ergonomi Indonesia

(The Indonesian Journal of Ergonomic)

massa tubuh, subjek termasuk dalam kategori normal. Begitu juga dari formulir biodata yang telah diisi subjek diperoleh data bahwa semua sudah pernah memiliki pengalaman kerja di bidang tata hidangan baik saat training maupun saat sebagai daily worker selama $6-12$ bulan. Selain itu kondisi kesehatan subjek telah dicek oleh petugas kesehatan yaitu dokter umum dan diperoleh hasil bahwa semua subjek dalam kondisi baik atau sehat dan tidak ada yang pernah patah tulang. Hal ini menunjukkan bahwa kondisi fisik subjek dalam kondisi yang baik dengan tubuh termasuk ideal.

Data antropometri yang diukur antara lain tinggi siku saat berdiri untuk mengetahui rerata posisi/ tinggi benda yang dibawa (dalam hal ini piring), saat menyajikan makanan ke meja tamu. Berdasarkan hasil pengukuran tinggi siku saat berdiri berada pada rentangan 102,00 - 115,00 cm. Sedangkan jarak benda yang dibawa dari tubuh subjek dapat dilihat dari panjang siku sampai pergelangan tangan, yaitu pada rentangan $23,00-30,00 \mathrm{~cm}$ dan rerata $27,86 \mathrm{~cm}$. Ini menunjukkan jarak vertikal benda masih di zona aman namun jarak horizontal benda diluar jarak aman yang disarankan (maksimum $25 \mathrm{~cm}$ ) sehingga risiko cedera makin tinggi.

Pengukuran antropometri telapak tangan dilakukan untuk mengetahui rerata panjang dan lebar telapak tangan serta tinggi ibu jari subjek, guna mengetahui apakah ukuran telapak tangan sudah sesuai dengan ukuran peralatan (piring) yang digunakan sebagai pengganti piring sebelumnya. Rerata suhu kering di tempat penelitian pada periode satu adalah 25,56 $\pm 0,38{ }^{\circ} \mathrm{C}$, sedangkan rerata suhu kering pada periode dua adalah $25,56 \pm 0,94{ }^{\circ} \mathrm{C}$. Data rerata suhu basah di tempat penelitian pada periode satu adalah $22,86 \pm 0,61{ }^{\circ} \mathrm{C}$, sedangkan rerata suhu basah pada periode dua adalah $22,42 \pm 0,69{ }^{\circ} \mathrm{C}$. Dari data suhu kering dan suhu basah yang diperoleh kemudian dipetakan ke dalam Psychromatric Chart untuk mendapatkan kelembaban relatif. Hasil dari pemetaan diperoleh kelembaban relatif pada periode satu adalah 85,28 $\pm 2,54 \%$ sedangkan pada periode dua adalah $83,33 \pm 2,81 \%$. Untuk intensitas cahaya diperoleh bahwa pada periode satu sebesar 251,34 $\pm 1,46$ Lux, dan pada periode dua sebesar 252,69 \pm 1,23 Lux. Sedangkan untuk rerata kecepatan udara pada periode satu adalah $0,01 \pm 0,01 \mathrm{~m} / \mathrm{dt}$, dan pada periode dua adalah $0,01 \pm 0,01 \mathrm{~m} / \mathrm{dt}$. Hal ini menunjukkan bahwa kondisi lingkungan kerja untuk para praktikan baik pada periode satu maupun periode dua masih dalam batas-batas adaptasi untuk melakukan suatu aktivitas kerja. Begitu juga dengan hasil uji kemaknaan kondisi lingkungan kedua periode menunjukkan 
ISSN Print : 1411 -951 X, ISSN Online : 20503-1716

Jurnal Ergonomi Indonesia

(The Indonesian Journal of Ergonomic)

bahwa memiliki karakteristik lingkungan yang sama.

Aktivitas menyajikan makanan dengan membawa empat piring sekaligus ke meja tamu termasuk jenis pergerakan manipulative, dimana aktivitas handling pada peralatan kerja menggunakan jari atau tangan. Selain itu posisi jari yang memegang piring ada yang menjepit dan ada yang menopang piring sehingga kekuatan jari tidak optimal. Pada saat menggunakan piring chop plate, tangan khususnya dari pangkal ibu jari dan jarijari terasa nyeri, ini disebabkan karena massa dan dimensi piring yang besar menyebabkan tekanan yang cukup keras terhadap otot tangan dan jari. Suplai oksigen ke otot menurun, proses metabolisme karbohidrat terhambat dan sebagai akibatnya terjadi penimbunan asam laktat yang menyebabkan timbulnya rasa nyeri otot (Kroemer and Grandjean, 2000). Oleh sebab itu penggunaan dinner plate yang lebih antropometris tentunya lebih mudah dipegang dan dapat mengurangi tekanan pada jari-jari sehingga asupan oksigen ke otot jari tangan tidak terhalangi dan dapat memberikan kekuatan yang memadai saat memegang piring.

Penelitian serupa juga dilakukan oleh Roger et al. (2008) yang menyatakan bahwa antropometri tangan dapat digunakan untuk perancangan alat-alat tangan maupun untuk fasilitas olah raga yang berkaitan dengan penggunaan tangan. Rancangan alat tangan yang ergonomis bertujuan untuk mengoptimalkan handle agar efektif dalam melakukan aktivitas untuk mengurangi beban pada otot, tendon kulit dan sendi. Begitu juga dengan penelitian yang dilakukan oleh Mandahawi et al. (2008), dimana rancangan peralatan tangan yang antropometris digunakan untuk mengurangi tekanan kontak pada karpal dan untuk menghindari cedera pada pergelangan tangan. Permasalahan yang terjadi dalam perancangan peralatan tangan adalah ketidaksesuaian antara dimensi peralatan dengan data antropometri. Ketidaksesuaian ini menyebabkan ketidaknyamanan, kecelakaan, tekanan biomekanik, kelelahan, cedera dan cummulative trauma disorders serta dapat berdampak terhadap penurunan produktivitas.

Penurunan kelelahan terjadi karena terdapat perbedaan dimensi piring yang digunakan saat menyajikan makanan pada American service pada periode satu dan dua. Piring yang digunakan untuk menyajikan makanan pada American service pada periode dua lebih sesuai dengan antropometri subjek. Penggunaan piring yang lebih antropometris adalah penggunaan piring dinner plate yang lebih ringan dan memiliki diameter lebih kecil dari piring sebelumnya (chop plate) 
ISSN Print : 1411 -951 X, ISSN Online : 20503-1716

Jurnal Ergonomi Indonesia

(The Indonesian Journal of Ergonomic)

Vol.2, No.1 : 1 Januari-Juni 2016

sehingga lebih nyaman dibawa saat harus membawa empat piring sekaligus saat menyajikan ke meja tamu. Hal ini disebabkan karena dengan menggunakan dinner plate akan lebih mudah untuk dipegang sehingga dapat bergerak dengan lebih rileks tanpa ada tekanan baik secara fisik pada otot-otot jari yang dapat menimbulkan rasa nyeri maupun secara mental takut akan terjatuhnya piring yang dipegang. Kondisi tersebut tentunya dapat menimbulkan rasa tenang dan senang sehingga dapat bekerja lebih semangat dan kelelahan tidak cepat menghampiri.

Penelitian serupa juga telah dilakukan oleh McDowell et al. (2012) yang menyatakan bahwa ukuran pegangan (the handle size) secara signifikan mempengaruhi kekuatan pegangan yang diukur dengan kedua jenis pegangan dinamometer. Efek menangani ukuran lebih jelas dengan pegangan Jamar, terutama pada pegangan diameter/span kecil. Komponen tertinggi gaya pegangan yang diamati dengan gagang silindris ditemukan di ujung jari. Maka dengan adanya perlakuan mengganti chop plate dengan dinner plate yang memiliki massa dan dimensi piring yang lebih kecil dan lebih sesuai dengan antropometri subjek, dapat menurunkan keluhan subjektif secara bermakna. Hal serupa juga dikatakan oleh Anema et al. (2004; dalam Del Prado-Lu, 2007), bahwa pengukuran

antropometri yang diperoleh dalam penelitian dapat diterapkan untuk meningkatkan penanganan barang secara manual, postur, permukaan dan desain furniture, desain dan tata letak tempat kerja, serta banyak lainnya. Pelayanan yang diberikan dapat dilakukan dengan lebih cepat, tepat dan ramah sehingga dapat memberikan kesan yang lebih baik terhadap tamu. Makin cepat pelayanan tentunya menunjukkan bahwa kinerja karyawan (dalam hal ini subjek) makin baik dan tentunya akan mampu memberikan dampak positif terhadap kepuasan konsumen. Seperti dalam penelitian Widjoyo dkk. (2013) yang menyatakan bahwa kecepatan pelayanan merupakan salah satu indikator dari dimensi responsiveness yang paling dominan mempengaruhi kepuasan konsumen salah satu restoran cepat saji di Surabaya.

Berdasarkan hasil penelitian bahwa data kualitas penyajian menunjukkan adanya peningkatan skor sebesar 189,39\% dari rerata skor $3,11 \pm 1,08$ pada periode satu menjadi $9,00 \pm 0,97$ pada periode dua. Peningkatan skor pada check list kualitas penyajian menunjukkan bahwa indikatorindikator penyajian yang berkualitas dapat dilakukan demi terwujudnya kepuasan konsumen. Hal ini disebabkan karena dengan menggunakan piring yang lebih antropometris, subjek merasa lebih 
ISSN Print : 1411 -951 X, ISSN Online : 20503-1716

Jurnal Ergonomi Indonesia

(The Indonesian Journal of Ergonomic)

nyaman dan mudah memegangnya sehingga tidak ada beban dalam membawanya, dapat bergerak lebih cepat dan aman (tidak mudah jatuh). Penataan piring di tangan kiri juga dapat dilakukan dengan benar dan rata/sejajar sehingga posisi piring tidak merusak penampilan makanan yang ada di atas piring yang lain. Selain itu piring tidak menyentuh pada bagian depan tubuh dan dapat melayani tamu dengan ramah dan sopan. Sesuai kriteria tingkat kualitas penyajian yang dicantumkan pada cheklist maka dapat dikatakan bahwa rerata kualitas penyajian subjek termasuk tinggi. Semakin tinggi reratanya berarti semakin baik dan semakin sesuai dengan standar kualitas penyajian yang diterapkan. Hal ini tentunya juga akan berdampak pada makin baiknya kinerja pelayanan yang ditunjukkan oleh subjek (dalam hal ini sebagai staf di restoran). Subjek dapat melakukan tugasnya dengan efektif, nyaman, aman, sehat dan efisien sekaligus menyenangkan serta dapat memberikan pelayanan yang lebih ramah dan penuh perhatian kepada tamu.

\section{IV.SIMPULAN DAN SARAN}

Berdasarkan dari hasil analisis dan pembahasan, dapat disimpulkan bahwa penggunaan dinner plate yang antropometris pada American service meningkatkan kinerja pelayanan dilihat 
ISSN Print : 1411 - $951 \mathrm{X}$, ISSN Online : 20503-1716

Jurnal Ergonomi Indonesia

(The Indonesian Journal of Ergonomic)

Strength. International Journal of Industrial Ergonomics. Volume 42. Issue 2. Pages 199-205.

Rogers, M. S., Barr, A. B., Kasemsontitum, B., and Rempel, D. M. 2008. A Three-dimensional Anthropometric Solid Model of The Hand Based on Landmark Measurement. Ergonomics, Vol.51, No.4, pp.511-526.

Widjoyo, I.O., Leonid, J.R., Yohanes, S.K. 2013. Analisis Pengaruh Kualitas Layanan terhadap Kepuasan Konsumen pada Layanan Drive Thru McDonals's Basuki Rahmat di Surabaya. Jurnal Manajemen Pemasaran, Vol. 1, No.1. Universitas Petra. 